\title{
Neither Fish, nor Fowl: Honeybees and the Parameters of Current Legal Frameworks for Animals, Wildlife and Biodiversity
}

\author{
Opi Outhwaite*
}

\begin{abstract}
The regulation of animals falls into three main paradigms; animal health, animal welfare and conservation. This article argues that in the modern context there are several regulatory challenges which are not accommodated within those parameters including those presented by contemporary issues such as animal diseases and hybrid and feral animals. A case study of honeybees is used to explore these frameworks and their parameters and limitations in detail. The difficulties arising are not confined to idiosyncratic cases such as honeybees however, but also apply at a broader level. While some of these difficulties might be tackled through incremental changes to existing legislation, a more holistic framework which moves beyond historical assumptions about the nature of animals and their relationship with people therefore, will ultimately be needed.
\end{abstract}

KEYWO RD S : animals, wildlife, conservation, animal health, animal welfare

\section{INTRODUCTION}

The way that animals are categorised and conceptualised within legal frameworks has implications for the responsibilities and protections offered to them. Currently regulatory responses fall into three prevailing paradigms: animal health, animal welfare, and conservation, but these paradigms do not adequately accommodate the complexities of contemporary regulatory challenges. This applies not only in idiosyncratic cases, but also for wider issues including significant, emerging challenges notably here the question of diseases in wild animals. This article aims to identify and analyse the prevailing regulatory paradigms, considering their boundaries and legal assumptions, to assess how these limit the ability of these frameworks to offer reflexive and effective responses to given regulatory objectives and challenges and to consider the implications of these and possible ways forward.

Section 2 addresses the nature and content of the three prevailing regulatory paradigms: animal health, animal welfare, and conservation, unpicking their historical development and the consequent parameters of each. Section 2 also offers a brief

* Senior Lecturer in Law at the University of Greenwich, (o.m.outhwaite@gre.ac.uk).

(c) The Author 2017. Published by Oxford University Press. All rights reserved.

For Permissions, please email: journals.permissions@oup.com 
introduction to the main legislative arrangements currently in place within each of the three paradigms, emphasising key provisions and concepts. In Section 3 the case study of honeybees is developed in detail. First the problem and implications of declining honeybee populations is described, with specific focus on the impact of pests and diseases - a key concern for honeybee populations. This is followed by analysis of the applicability of each of the paradigms to this issue. The analysis draws out the complex categorisation issues and assumptions about the differing roles of animals-here specifically honeybees-and the regulatory spaces that they may occupy. In doing so, this Section makes clear that none of the existing paradigms fits comfortably onto the honeybee problem. Section 4 builds on and broadens the analysis to consider how the underlying limitations in each of the three paradigms restrict the applicability of otherwise relevant measures not only to honeybees, but also to other animals and species and to consider the deeper conceptual problems in the distinctions made within the law. Finally, the article considers some of the changes which might begin to shift the law towards more effective ways of conceptualising and regulating animals. Responding to current limitations will involve moving beyond traditional parameters. Emerging issues call for a more holistic approach to animals in the law and even where narrower anthropocentric concerns are the focus of regulation, the distinctions traditionally made are not tenable. Extending the parameters of existing frameworks offers some opportunities to address current limitations, but may not go far enough in overcoming conceptual problems and correspondingly inflexible frameworks.

\section{CURRENT PARADIGMS FOR ANIMALS AND THE LAW}

\subsection{Animal health}

'Animal health' is the regulatory framework within which pests and diseases are managed and focuses on animals kept for agricultural purposes-commonly, 'livestock' or 'farmed animals'. In responding to pest and disease risks, the animal health framework makes a number of distinctions between different types of animals and the circumstances in which disease controls will apply. The historical development of the animal health framework provides the basis for these distinctions: animal health has been concerned with protecting livestock producers and other keepers of economically important animals from the losses associated with disease outbreaks and this remains the focus of animal health. ${ }^{1}$ Early efforts in animal health responded to particular disease outbreaks. The veterinary health service was introduced in response to an outbreak of rinderplast, and movement restrictions and powers to order the destruction of infected animals were introduced under the Cattle Diseases Act 1866 which expanded on provisions of the Sheep Pox Acts of $1848 .^{2}$ Animal health

1 See further John McEldowney, Wyn Grant and Graham Medley, The Regulation of Animal Health and Welfare: Science, Law and Policy (Routledge 2013); David Carslake and others, 'Animal Health and Welfare : A Case Study of Science, Law And Policy in a Regulatory Environment' (2010) 3 Law, Society and Policy 227.

2 Clive Spinage, Cattle Plague: A History (Kluwer/Plenum 2003); Abigail Woods, A Manufactured Plague: The History of Foot-and-Mouth Disease in Britain (Earthscan 2004); Abigail Woods, 'The Construction of Animal Plague: Foot and Mouth Disease in Nineteenth-century Britain' (2004) 17 Social History of Medicine 3. 
efforts at this time predated the current understanding of diseases and their epidemiology and of veterinary medicine, ${ }^{3}$ but killing infected animals or preventing their entry into the country was successful in controlling disease outbreaks. ${ }^{4}$ The animal health framework was therefore reactive, with legislation for particular diseases introduced usually as a consequence of an outbreak of that disease and in response to public health crises. ${ }^{5}$

The existing animal health framework is notable for its multitude of legislative instruments, both domestic and EU, with legislation often species and disease specific. ${ }^{6}$ The key enabling Act for England and Wales is the Animal Health Act 1981 but this is implemented by dozens of pieces of secondary legislation and further Acts. ${ }^{7}$ Within this framework, livestock animals are routinely subject to mandatory controls and these tend to be based around a system of compulsory registration, movement controls, and surveillance designed to minimise the risk of diseases being spread and to ensure traceability in the event that there is a disease outbreak. ${ }^{8}$

Registration of the animals themselves or their keepers enables the regulatory authority to maintain an up-to-date and accurate picture of their presence which can be used to support activities in disease surveillance, enforcement and education.

3 Jeff Waage and John Mumford, 'Agricultural Biosecurity' (2008) 363 Philosophical Transactions of the Royal Society 863.

4 Carslake and others (n 1 ).

5 Opi Outhwaite, 'Legal Frameworks for Biosecurity' in Andrew Dobson, Kezia Barker and Sarah Taylor (eds), Biosecurity: Theory and Politics in Practice (Routledge/Earthscan 2013). See also Mike Radford, Animal Welfare Law in Britain; Regulation and Responsibility (OUP 2001).

6 Animal health is an area of shared competence so while many instruments give effect to EU law there are also many which address specific issues of domestic importance or which provide for further matters-this is most clearly the case for bovine tuberculosis. For a comprehensive review of animal health legislation see Opi Outhwaite, 'Obligations and Flexibilities in Animal Health Legislation' (unpublished Defra April 2013).

7 Including the Animal Health Act 2002 which makes particular provision for responses to Foot and Mouth Disease and transmissible spongiform encephalopathies (TSEs).

8 With an emphasis on cattle for example, see: Disease Control (England) Order 2003, SI 2003/1729 [as amended]; Cattle Identification Regulations 2007, SI 2007/529 [as amended]; Regulation EC 1760/2000 establishing a system for the identification and registration of bovine animals and regarding the labelling of beef and beef products and repealing Council Regulation (EC) No 820/97; Movement of Animals (Restrictions) (England) Order 2002, SI 2002/3229; Council Directive 2000/75/EC of 20 November 2000 laying down specific provisions for the control and eradication of bluetongue; Commission Regulation (EC) No 1266/2007 of 26 October 2007 on implementing rules for Council Directive 2000/ $75 / \mathrm{EC}$ as regards the control, monitoring, surveillance and restrictions on movements of certain animals of susceptible species in relation to bluetongue [2007] OJ L287/37; Zoonoses (Monitoring) (England) Regulations 2007, SI 2007/2399; Zoonoses Order 1989, SI 1989/285; Products of Animal Origin (Disease Control) (England) Regulations 2008, SI 2008/465; The Products of Animal Origin (Disease Control) (England) (Amendment) Regulations 2009, SI 2009/1297; Enzootic Bovine Leukosis Order 2000, SI 2000/2056; Transmissible Spongiform Encephalopathies (England) Regulations 2010, SI 2010/ 801; Bovine Semen (England) (Amendment) Regulations 2011, SI 2011/254; The Animal By-Products (Enforcement) (England) Regulations 2013, SI 2013/2952. This is not a complete list: see Outhwaite (n 6). For an overview of guidance see, for cattle: <https://www.gov.uk/topic/keeping-farmed-animals/cat tle-identity-registration $>, \quad<$ https://www.gov.uk/topic/keeping-farmed-animals/cattle-movement $>$; for pigs: <https://www.gov.uk/topic/keeping-farmed-animals/pig-identity-registration-movements >; for sheep: <https://www.gov.uk/topic/keeping-farmed-animals/sheep-identity-registration>; for poultry: $<$ https://www.gov.uk/topic/keeping-farmed-animals/poultry-registration > (all links accessed 18 January 2017). 
Movement controls, designed to prevent the movement of infected animals (and contaminated equipment) from one place to another can include record-keeping, permitting requirements for movements in normal (disease free) circumstances and the imposition of movement restrictions in the event that disease is identified or suspected. Treatment or destruction of animals will also be provided for in the event of confirmed or suspected disease presence and in many cases is supported with a system of compensation. In addition to these 'in country' controls there are several provisions applicable to the trade in animals and animal products, both within the EU and between the EU and third countries which aim to prevent the arrival of diseases into the EU and also therefore into the $\mathrm{UK}^{9}{ }^{9}$

\subsection{Animal welfare}

While animal health is focused on economically important livestock animals, early efforts to protect animals from cruelty related only to domesticated animals ${ }^{10}$ and this focus is largely reflected in the continuing parameters of the animal welfare framework. Prevailing moral and social values — which will be time and context specificare noted by Harrop to be an important influence on the development of animal welfare. ${ }^{11}$ 'Animals' - encompassing companion animals, livestock and other 'kept' animals - have historically been considered as property, with early cruelty offences seeking to protect not the welfare of animals but the interests of property owners (as well as seeking to preserve public order). ${ }^{12}$ While this at an early stage limited the development of animal welfare, it perhaps also enabled the development of a view that animals, because they were subject to human control, should be protected from cruelty and subject to certain protections, with human keepers or owners placed in a guardianship role. ${ }^{13}$ Robertson notes, for example that:

Essentially, the law reflects a scale of 'responsibility' regarding animals, depending on their uses, and reliance on human care-givers. For example, there are legal obligations regarding companion animals which largely reflect the law's approach that if an animal is significantly dependent on a human being for its food, water, shelter, health and overall well-being, then it is appropriate to apply equally significant legal accountabilities to the caregiver. Similarly, if society wishes to benefit from animals (eg, in agriculture or research), then people justifiably have a greater duty of care to those animals in comparison to those that exist in the wild. ${ }^{14}$

This position means that while animal welfare has progressed steadily to offer more comprehensive protection over time, wild animals, by contrast, have been viewed as

9 See <http://ec.europa.eu/food/animals/index_en.htm> accessed 18 January 2017.

10 Radford (n 5) 77.

11 Stuart R Harrop, 'The Dynamics of Wild Animal Welfare Law' (1997) 9(2) JEL 287.

12 See, for example, discussion by Ian Robertson, Animals, Welfare and the Law: Fundamental Principles for Critical Assessment (Routledge 2015); McEldowney and others (n 1).

13 Peter Fitzgerald, 'Good Badger Bad Badger: The Impact of Perspective on Wildlife Law and Policy' (2013) $10 \mathrm{~J}$ of Animal \& Natural Resource L 41; Robertson (n 12). 
separate and treated as something to be controlled (where necessary, for example through hunting or pest control) or as a resource to be exploited or managed (including for leisure). ${ }^{15}$ Although the law does, in some limited circumstances, protect wild animals from suffering, there is no overarching acceptance within the law that wild animals can and do suffer nor that they should be protected from suffering. ${ }^{16}$ Harrop argues that such legal protection of wild animals as does exist is largely incidental, resulting from measures with conservation aims ${ }^{17}$ and while some specific offences apply to wild animals (see below) these are restrictively drawn in terms of both scope and species coverage.

The current framework for animal welfare extends beyond specific offences of cruelty to protect animal welfare more broadly and to minimise or prevent suffering in animals. Typically, this framework addresses domesticated animals including companion animals (pets) with some separate measures specifically applicable to the conditions in which farm animals are kept. ${ }^{18}$

At the EU level several instruments establish minimum standards for the protection of farmed animals on a species specific basis; ${ }^{19}$ there is no overarching EU framework on the welfare of pets. ${ }^{20}$ Domestically however, the legal framework takes a more encompassing approach to animal welfare and includes companion animals as a central focus of the legislation. In England and Wales, the Animal Welfare Act 2006 (the AWA 2006) is the principal legislation for animal welfare and places a broad duty on persons responsible for an $\operatorname{animal}(s)$ to ensure the welfare of that

Law Commission, Wildlife Law (Consultation Paper No 206, 2012); Gareth Spark, 'Protecting Wild Animals from Unnecessary Suffering' (2014) 26 JEL 473; Fitzgerald (n 13); Joan E Schaffner, An Introduction to Animals and the Law (Palsgrave Macmillan 2011).

16 Spark (n 15) and see the Wild Mammals (Protection) Act 1996.

17 Stuart Harrop, 'The Dynamics of Wild Animal Welfare Law' (1997) 9 JEL 287; Radford (n 5). Conversely, it has also been argued that species specific conservation measures arose principally from animal welfare efforts. (McEldowney, Grant and Medley (n 1); this view is perhaps better understood with a view to the idiosyncratic protection offered to some species, such as badgers and deer.

18 In addition to the 2006 Act the Welfare of Farmed Animals (England) Regulations, SI 2007/2078 (as amended) establish further conditions on the keeping of farmed animals with specific conditions for hens, calves, pigs and rabbits. This regulation gives effect to several applicable pieces of EU legislation on farm animal welfare. In some specific but much more limited instances wild animals are protected through cruelty offences but are not subject to wider animal welfare measures.

19 Typically these establish minimum space requirements, maximum stock density and some requirements concerning feeding and treatment in the event of injury or illness, with separate measures providing for welfare during transport. See Council Directive 1999/74/EC laying down minimum standards for the protection of laying hens [1999] OJ L203/53; Council Directive 2007/43/EC laying down minimum rules for the production of chickens kept for meat production [2007] OJ L182/19; Council Directive 2008/119/EC laying down minimum standards for the protection of calves [2009] OJ L10/7; Council Directive 2001/88/EC amending Directive 91/630/EEC laying down minimum standards for the protection of pigs [2001] OJ L316/4; Council Directive 2001/93/EC amending Directive 91/630/EEC laying down minimum standards for the protection of pigs [2001] OJ L316/36.

20 Though Art 13 of Treaty of the functioning of the European Union (TFEU) provides 'In formulating and implementing the Union's agriculture, fisheries, transport, internal market, research and technological development and space policies, the Union and the Member States shall, since animals are sentient beings, pay full regard to the welfare requirements of animals, while respecting the legislative or administrative provisions and customs of the Member States relating in particular to religious rites, cultural traditions and regional heritage'. 
animal. $^{21}$ That duty means taking reasonable steps to meet the animal's needs including (1) its need for a suitable environment, (2) its need for a suitable diet, (3) its need to be able to exhibit normal behaviour patterns, (4) any need it has to be housed with, or apart from, other animals, and (5) its need to be protected from pain, suffering, injury and disease. ${ }^{22}$ Failure to fulfil the duty constitutes an offence but where a person is failing in their duty, improvement notices can be issued by an inspector, specifying steps to be taken to achieve compliance. ${ }^{23}$ In addition, the Act establishes further offences including an offence of causing unnecessary suffering. ${ }^{24}$ A crucial component of the AWA is the assumption of sentience in order for animal welfare provisions to apply. 'Animals' for the purpose of the AWA 2006 means 'vertebrates other than man' ${ }^{25}$ and it is only this category of animals that are assumed to meet the sentience requirement. ${ }^{26}$

\subsection{Conservation}

In the framework of conservation, the objects of regulation are wild animals. Conservation laws, like animal health, developed from a reactive position, addressing specific issues as they were identified. ${ }^{27}$ They also focused on the need to conserve species in terms of utility and the avoidance of over-exploitation (from an anthropocentric perspective) and on cruelty offences that related to this utility. As noted by Bell, McGillivray and Pedersen, protection of individual animals is largely done on an ad hoc basis ${ }^{28}$ and protection of wild animals from a conservation perspective is by no means comprehensive. Similarly to animal welfare, there has been no overarching assumption that animal species should be protected.

Conservation laws, in their early development, also maintained boundaries from agriculture, land management, and private property rights and from amenity and cultural value. ${ }^{29}$ While more integrated approaches to land use (seeking to reconcile agricultural and environmental needs) have since developed such distinctions are still to be observed in current conservation legislation and, as they apply to wild animals, further reflect the assumption that the conservation of species is to fit in with the resource needs of humans or assumptions about the animals utility.

The current legal framework addresses both individual species and habitat conservation. Whereas animal welfare is concerned with the condition of animals at an individual level, the framework for conservation focuses on population or species level protection and in this regard seeks to protect animals which are considered threatened or are otherwise prioritised. As with the other frameworks, conservation is an

21 The AWA $2006 \mathrm{~s} 9$ (1).

22 ibid s 9: duty of person responsible for animal to ensure welfare.

23 ibid s 10.

24 ibid s 4. See further offences in ss 5-8.

25 ibid s 1(1).

26 ibid, Note 11, Explanatory Note.

27 Stuart Bell, Donald McGillivray and Ole Pedersen (eds), Environmental Law (8th edn, OUP 2013) at 801; Colin Reid, Nature Conservation Law (2nd edn, Sweet \& Maxwell 2002) ch 3.

28 Bell, McGillivray, and Pedersen, ibid 803. And see Law Commission, Wildlife Law Final Report, Volume 1, (Law Com No 362 2015) ch 1.

29 Bell, McGillivray, and Pedersen (n 27). See also Reid (n 27) on the [lack of] ownership of wild animals: 18-19. 
area in which the domestic legislative framework gives effect to a number of instruments at EU level including the Habitats Directive ${ }^{30}$ and the Birds Directive. ${ }^{31}$ In addition, some wild animals are afforded protection at the domestic level through species specific legislation or other ad hoc measures (for instance, the Protection of Badgers Act 1992 and the Deer Act 1991).

Under existing arrangements in England and Wales the general protection of animal species is achieved through several separate pieces of legislation. ${ }^{32}$ The Wildlife and Countryside Act 1981 (WCA 1981) establishes offences aimed at the protection of wild animals and in this regard has some overlap with animal welfare. Specifically Part 1 of the WCA 1981 provides for the protection of birds, as identified in listed Schedules, by establishing offences concerning the taking or destruction of nests or eggs and the killing, taking or injury of wild birds. Elsewhere, the WCA provides for the 'protection of certain wild mammals', establishing offences equivalent to those in Part $1 .^{33}$ Reflecting historical divisions, the protection of certain wild animals under section 9 of the WCA 1981 is subject to a number of exclusions including where the action is taken under specified agriculture or animal health Acts or where it is necessary for the purpose of preventing damage to livestock, foodstuff for livestock, crops, vegetables, fruit, growing timber or any form of property or fisheries. ${ }^{34}$ Similar exclusions apply in the Habitats Regulations.

With respect to conservation more broadly, the Natural Environment and Rural Communities Act 2006 sets out the duty of public authorities to conserve biodiversity; this is pursued through the listing of organisms and habitats which are regarded as of principal importance. ${ }^{35}$ The Conservation of Habitats and Species Regulations 2010 (the Habitats Regulations) also provide for species protection, implementing the requirements of the EU Habitats Directive. ${ }^{36}$ Part 3 of the Habitats Regulations provides for the protection of species and applies to 'European protected species' which have a natural range in Britain. ${ }^{37}$ In addition, offences are established for the protection of certain wild animals, these include European protected species but also, in some circumstances (deliberately disturbing animals) to any wild species. $^{38}$

\section{ADDRESSING DECLINING HONEYBEE POPULATIONS WITHIN THE CURRENT LEGAL PARADIGMS}

This section uses a case study of honeybees to explore the limits of the paradigms presented in Section 2. The problem of honeybee decline is one which has seen calls

30 Council Directive 92/43/EEC of 21 May 1992 on the conservation of natural habitats and of wild fauna and flora [1992] OJ L206/7.

31 Council and Parliament Directive 2009/147/EC on the conservation of wild birds [2009] OJ L20/7.

32 Separate legislation applies to marine and coastal protection.

33 s 9 establishes an offence of intentionally killing, injuring or taking listed wild mammals. See listed animals in Schedule 5 and see further s 11: prohibition on certain methods of killing or taking wild animals and $\mathrm{s}$ 12: protection of certain mammals.

34 WCA 1981 s 10.

35 Natural Environment and Rural Communities Act 2006 ss 40-41.

36 Council Directive 92/43/EEC (n 30).

37 As listed in Schedule 2 of the Regulation. See ss $40-43$ on protection of animals.

38 Habitats Regulations, see s 40(1)(a) and (b). 
for an urgent response, ${ }^{39}$ but in the context of these paradigms it is not clear that the law is able to respond effectively to this contemporary problem. This section analyses the application of each of the three paradigms to the honeybee problem and in doing so identifies some of the key conceptual difficulties that are more broadly applicable and which are discussed in later sections.

\subsection{Honeybees in England and Wales}

Bees, including honeybees, are the one of the world's most important pollinators of flowering plants, ${ }^{40}$ and make an important contribution to the provision of pollination services, which are a key ecosystem service. ${ }^{41}$ In addition to their inherent value as a species, including as a component of biodiversity, pollination services provided by honeybees contribute to plant genetic diversity and to the availability of a number of agricultural crops, particularly fruits. ${ }^{42}$ The economic value to UK agriculture of pollination by honeybees has been estimated at $£ 200 \mathrm{~m}$ per year. ${ }^{43}$ Honeybees, of course, also produce honey and other products such as beeswax; the estimated value of honey in the UK is between $£ 10$ and $35 \mathrm{~m}$, per annum, depending on yield. ${ }^{44}$ As well as having economic and ecological value honeybees have with respect to social amenity, with beekeeping providing a hobby or 'leisure activity' to thousands of people annually. In England and Wales honeybees also have a social value in so far as they share (with certain other plants and animals) iconic status in relation to the English countryside and heritage. ${ }^{45}$ The economic value of such contributions is of course difficult to quantify, though perhaps not impossible; work on the assessment of ecosystem services attempts to make such calculations. ${ }^{46}$

The majority of honeybees in England and Wales are managed-that is, they are kept by beekeepers. A small proportion of honeybees are managed on a commercial

39 For example, in the UK the Insect Pollinators Initiative was a $£ 10 \mathrm{~m}$ joint funding initiative which sought to address pollinator declines including through funding focused on honey bee pests and diseases. The initiative was supported by the Biotechnology \& Biological Sciences Research Council (BBSRC), the Department for Environment, Food \& Rural Affairs (Defra), the Natural Environment Research Council (NERC), the Wellcome Trust and the Scottish Government.

40 Andrew Cuthbertson and Mike Browne, 'Issues Affecting British Honeybee Biodiversity and The Need for Conservation of This Important Ecological Component' (2009) 6 Int J Environ Sci Tech 695; Andrew Byrne and Úna Fitzpatrick, 'Bee Conservation Policy At The Global, Regional And National Levels' (2009) 40 Apidologie 194.

41 See for instance Joseph Alcamo and others, Ecosystems and Human Well-Being: A Framework for Assessment (Island Press 2003); Claire Kremen, 'Crop Pollination Services from Wild Bees', in Rosalind James and Theresa Pitts-Singer (eds), Bee Pollination in Agricultural Ecosystems (OUP 2008).

42 Alexandra-Maria Klein and others, 'Importance of Pollinators in Changing Landscapes for World Crops' (2007) 274 Proceedings of the Royal Society B, 303.

43 National Audit Office \& Department for Environment, Food and Rural Affairs (DEFRA); The Health of Livestock and Honeybees in England, Report by the Comptroller and Auditor General, (HC 288 Session 2008-2009, 4 March 2009) 12 and Appendix II.

44 National Audit Office \& DEFRA, ibid 28.

45 This is recognised by DEFRA, for instance, in DEFRA, Bees and Other Pollinators: their Value and Health in England. Review of Policy \& Evidence (July 2013) and can be witnessed in the wide array of goods and works which depict the honeybee and beekeeping as part of the British countryside.

46 The Economics of Ecosystems and Biodiversity, UK National Ecosystem Assessment, Preliminary Synthesis and Progress Report on Status and Trends, (Report of the co-chairs February 2010) < http://www.teeb web.org/> accessed 18 January 2017. 
basis but the majority are managed on both a small-scale and a non-commercial basis. As will be explored below, the status and legal characterisation of nonmanaged bees sometimes breaks down: there are populations of feral bees living wild (ie living separately from the direct influence or management of a beekeeper) while the presence of further 'wild' honeybee populations is disputed; honeybees are native to northern Europe, but there is limited data to confirm or disprove the presence or numbers of wild honeybees. ${ }^{47}$

Persistent indicators that the numbers of honeybees may be in serious decline are consequently of concern not only from a conservation perspective but also in terms of agriculture, food security and the economy. ${ }^{48}$ In England colony losses of at least $30 \%$ were reported for the winters of 2007-2008 and 2012-2013. Although losses in other years have been less drastic they are significantly higher than the 7-10\% considered sustainable. ${ }^{49}$ Responding to these losses is challenging because the causes are not well-understood. A number of factors have been implicated, including the use of agrochemicals, ${ }^{50}$ loss of habitat for forage (associated with industrial agriculture and inadequate availability of suitable natural habitat ${ }^{51}$ ) and, for honeybees in

47 There is no consensus on the number of honeybees living wild in the UK that may be considered 'wild' or 'feral'. See Ana Nieto and others, European Red List of Bees (Publication Office of the European Union 2014). Nieto and others comment that 'Numerous studies indicate that A. mellifera has undergone significant declines in Europe .... however, it is not clear if they refer to population reduction of wild or managed colonies although there are studies clearly documenting shifts in the number of managed hives.' See also Catherine Thompson, Giles Budge and Jacobus Biesmeijer, 'Feral Bees in the UK: The Real Story' Bee Craft (April 2010) 22.

48 The issue of honeybee losses is subject to focused and on-going research efforts but a number of studies and reports have indicated a problem of declining populations. See Jefferey Pettis and Keith Delaplane, 'Coordinated Responses To Honeybee Decline In The USA' (2010) 41 Apidologie 256; Simon Potts and others, 'Declines of Managed HoneyBees and Beekeepers' (2010) 49 European J of Apicultural Research 15; Peter Neumann and Norman Carreck, 'Honeybee Colony Losses' (2010) 49 J of Apicultural Research 1; Dennis van Engelsdorp. and Marina Meixner, 'A Historical Review of Managed Honeybee Populations In Europe And The United States And The Factors That May Affect Them' (2010) 103 Journal of Invertebrate Pathology S80; Renée Johnson, 'Honeybee Colony Collapse Disorder' Congressional Research Service Report January 7 2010, <https://digital.library.unt.edu/ark:/ 67531/metadc505392/> accessed 3 March 2017.

49 See The British Beekeepers' Association, BBKA Members Honey Bee Colony Winter Survival Survey for 2014 /2015, 25 June 2015, <http://www.bbka.org.uk/news_and_events/press_office/press_releases. php $>$ accessed 3 March 2017. See also The British Beekeepers' Association, Beekeepers fight back to ensure honeybees' survival, Tuesday 26 May 2010, <http://www.bbka.org.uk/news_and_events/news. php > accessed 3 March 2017.

50 The use of agrochemicals, in particular neonicitinoids, has also received significant attention as one of the factors contributing to the decline in honeybees including in a global context. The scientific basis for this discussion - in which data is contested - and the possibility of banning such pesticides is beyond the scope of this article since it focuses on issues other than those concerning the regulation of animals. The European Food Safety Authority distinguishes bee health issues, which are dealt with in the remit of animal health, from pesticides regulation. See however EFSA Panel on Plant Protection Products and their Residues (PPR) 'Scientific Opinion On The Science Behind The Development Of A Risk Assessment Of Plant Protection Products On Bees (Apis mellifera Bombus spp. and solitary bees)', 201210 EFSA J 2668 and see (n 48).

51 See, for example, Imperial College London Consultants, Honeybee Health (Risks) in England and Wales: Report to the National Audit Office (2008); Stefano Maini, Piotr Medrzycki and Claudio Porrini, 'The Puzzle Of Honey Bee Losses: A Brief Review' (2010) 63 Bulletin of Insectology 153; Cuthbertson and Brown (n 40); Laura Hannon and Thomas Sisk, 'Hedgerows In An Agri-Natural Landscape: Potential Habitat Value For Native Bees' (2009) 142 Biological Conservation 2140; And see British Beekeepers 
the UK especially, a decline in the number of beekeepers who play a role in managing these risks and sustaining populations. ${ }^{52}$ One factor which is widely recognised as negatively affecting the health of honeybees and honeybee colonies is the impact of pests and diseases. ${ }^{53}$ Corresponding measures are necessary therefore both to prevent the arrival of new pests and diseases and to manage the impact of those that are already present.

\subsection{Honeybees, disease control and the framework for animal health}

Given the significance that has been attached to pest and disease risks for declining honeybee populations, animal health might be the obvious framework through which to manage honeybee health risks. Within EU law, honeybees do fall within the remit of the animal health legislation for the purpose of movement into and within the EU: since there is an international trade in honeybees, they are regulated under the Balai Directive with requirements in place to prevent the introduction or spread of notifiable diseases. ${ }^{54}$ Beyond this however, within the domestic framework (for England and Wales), honeybees do not fall within the remit of animal health. From a regulatory perspective they are the responsibility of a separate agency. ${ }^{55}$ From a legislative perspective, honeybees are subject to standalone legislation in the form of the Bees Act 1980 (the 1980 Act) and the Bee Diseases and Pests Control (England) Order 2006 (the 2006 Order). ${ }^{56}$ Under the bee-specific legislation there are some notable differences in approach to controlling honeybee disease risks as compared with those of animals within the animal health framework.

Association, Honeybee Health Research Concepts (2009); Vicky Kindemba, The Impact Of Neonicotinoid Insecticides On Bumblebees, Honeybees And Other Non-Target Invertebrates (Buglife: the Invertebrate Conservation Trust 2009).

52 Parliamentary Office of Science and Technology (POST), 'Insect Pollination' (January 2010) Postnote 348. And see Imperial College London Consultants, ibid.

53 For discussion of the nature of relevant threats, both endemic and exotic, see Imperial College London Consultants (n 51) 7, and see further British Beekeepers Association (n 51); Ingemar Fries and Suresh Raina, 'American Foulbrood and African Honeybees (hymenoptera: apidae)' (2003) 96 J of Economic Entomology 6; Stephen Pernal and Adony Melathopoulos, 'Monitoring for American Foulbrood Spores from Honey and Bee Samples in Canada' (2006) 41 Apiacta 99; Selwyn Wilkins, Mike Brown and Andrew Cuthbertson, 'The Incidence Of Honeybee Pests And Diseases in England and Wales' (2007) 63 Pest Management Science 1062; Wolfgang Ritter and Pongthep Akratanakul, Honeybee Diseases And Pests: A Practical Guide (FAO 2006); Food and Environment Research Agency (FERA), Managing Varroa (2009).

54 Council Directive 92/65/EEC of 13 July 1992 laying down animal health requirements governing trade in and imports into the Community of animals, semen, ova and embryos not subject to animal health requirements laid down in specific Community rules referred to in Annex A(I) to Directive 90/425/EEC [1992] OJ L268/54. The Balai Directive sets out animal health requirements for 'other' animals (separately from common livestock animals which are subject to separate legislation). See DEFRA guidance on the Balai Directive <https://www.gov.uk/guidance/balai-directive-moving-live-animals-semen-and-em bryos $>$ accessed 18 January 2017.

55 Honeybees were until very recently regulated separately from animal health, within the remit of the Plant, Seed and Bee Health Inspectorates of the FERA. Plant and animal health has now been brought together under the Animal and Plant Health Agency (APHA), though specific responsibility for honeybees remains with the National Bee Unit (NBU). See APHA < https://www.gov.uk/government/organisations/ animal-and-plant-health-agency $>$ and National Bee Unit (NBU) <http://www.nationalbeeunit. com $>$ (both accessed 18 January 2017). 
Consideration of the risks posed by diseases of honeybees would appear to support the need for registration of beekeepers or their hives since by their nature bees are mobile and movement from one colony to another has seen diseases spread from one area to another. ${ }^{57}$ Consequently, in some jurisdictions, such as France and New Zealand, beekeepers with one or more hives must be registered because of the recognised animal health risks. In England and Wales although legal provisions in the 2006 Order aim to enable containment, treatment or eradication of diseases and pests, registration of beekeepers is currently voluntary rather than mandatory. ${ }^{58}$ In 2009, a period of heightened interest in beekeeping, figures reported by the NBU indicated that around 20,000 beekeepers were not registered. ${ }^{59}$ This has implications for surveillance and enforcement since random inspection and enforcement activities are based on the identification of beekeepers through 'BeeBase'. 60

Similarly, in contrast with most animal health controls, although the 2006 Order provides for standstill orders in the event that a notifiable pest or disease is confirmed, ${ }^{61}$ there are no provisions establishing routine movement controls for honeybees: no system for official notification, exchange of information, use of permits, or similar, is provided for. Bees may then, ordinarily, be moved freely from one area to another without that fact being recorded or communicated. Requirements for routine record keeping are also limited. Article 12 of the 2006 Order implies that there may be a record keeping obligation on beekeepers, providing that

a person in charge of bees, hives, combs, bee products, or appliances or the owner or occupier of premises or a vehicle in which there is suspected to be a notifiable pest shall... give such information (including information concerning the number, location and any movements of hives, bees [etc.] to an authorised person as that person shall reasonably require for the purposes of the Order. $^{62}$

Record keeping is not, however, provided for in the 1980 Act or elsewhere in the 2006 Order. If there is a record keeping requirement in this provision then it is vague and non-specific. Consequently beekeepers may not be aware of their [possible] legal responsibilities in this regard and, conversely, the legal basis for enforcement may be uncertain.

58 Despite the recognition that there is a need for increased involvement of beekeepers including through registration, the Healthy Bees Plan emphasises that this should take place only through voluntary registration. See DEFRA, Healthy Bees: Protecting and Improving the Health of Honeybees' (2009) 11.

59 Fera, Healthy Bees Plan - Quarterly Newsletter for all those interested in honeybee health, Issue 1 October 2009 (Fera 2009), <http://www.nationalbeeunit.com/index.cfm?sectionid $=41>$ accessed 3 March 2017.

60 The NBU uses BeeBase as the means to provide information, training and education to beekeepers and to increase awareness of the relevant legislation. The BeeBase register is also used to target inspection and surveillance activities. Beekeepers who are not registered are not subject to random inspections.

61 See art 3 and art 4(1) of the 2006 Order (n 56).

62 ibid art 12(1)(b). 
Where the importation or movement of animal products poses a pest or disease risk these are also often subject to mandatory animal health controls. ${ }^{63}$ For honeybees, apiary products, primarily in the form of honey, present a recognised risk. ${ }^{64}$ For this reason husbandry advice is that bees should not be fed on honey from an unknown source. ${ }^{65}$ There are controls in place for the importation of honey to be used exclusively in apiculture. ${ }^{66}$ Honey for human consumption, on the other hand, though it may expose bees to risks for example in the packing and movement prior to retail, is regulated not from an animal health perspective but as a consumer protection issue. ${ }^{67}$ This may be because it is not feasible or appropriate, in terms of disease risk or trade restrictions, to place honey for human consumption under such control. If this is the case then post-entry controls become important, again to reduce the likelihood that honeybees access potentially contaminated honey. To date however, there are no clear legal requirements related to this responsibility and specific biosecurity requirements or guidance have not been published. ${ }^{68}$ More limited regulatory powers also operate with respect to this aspect of surveillance. In contrast with the common position in animal health, ${ }^{69}$ the regulatory agency does not have powers to routinely enter and inspect honey packing plants and nor does it have other powers to routinely control disease risks at such plants unless there are reasonable grounds for suspecting that a notifiable disease is present (which does not

63 For example various legislative instruments (see n 8) establish restrictions on meat and other animal products and place requirements on slaughterhouses.

64 The Regulatory Impact Assessment for the 2006 Order clearly recognises the risk which bee and hive products pose (Explanatory Memorandum to The Bee Diseases and Pests Control (England) Order 2006, 2006 No 342, see s 5, <http://www.nationalbeeunit.com/index.cfm?sectionid=79> accessed 3 March 2017. FERA guidance recognises that certain diseases may also be spread by honey: ' . . apiary proximity to some commercial importers of honey or some sites used for the disposal of used honey barrels could be a risk factor for disease'. FERA, Information Note AFB infection- Analysis of Spread and Possible Risk Locations' (2010). See also Dirk de Graaf and others, 'Influence of the Proximity of American Foulbrood Cases and Apicultural Management on the Prevalence of Paenibacillus Larvae Spores in Belgian Honey' (2001) 32 Apidologie 587; Biosecurity New Zealand, Import Risk Analysis: Honeybee Products (Ministry of Agriculture and Forestry Wellington New Zealand 2004), <http:// www.agriculture.gov.au/biosecurity/risk-analysis/animal $>$ accessed 3 March 2017; Wolfgang Ritter, 'Early Detection of American Foulbrood by Honey and Wax Analysis' (2003) 38 Apiacta 125; Ritter and Akratanakul (n 53); Pernal and Melathopoulos (n 53).

65 FERA, Foul Brood Disease (n 57).

66 European Parliament and Council Regulation (EC) No 1774/2002 of 3 October 2002, laying down health rules concerning animal by-products not intended for human consumption [2002] OJ L273/1. See Chapter IX and Annex I.

67 The Honey (England) Regulations 2015 (SI 2015/1348) implement Council Directive 2001/110/EC, setting out honey specifications and requirements with respect to labelling and sale. Within this framework honey must be accompanied by a Model Health Certificate, the conditions of which address issues such as compliance with processing and production standards.

68 The 2006 Order ( $\mathrm{n}$ 56) imposes a very general notification obligation on a person who 'discovers in the course of his occupation' a 'bee pest that he knows or suspects is a notifiable pest'; see art 3(2). Honey importers and packers are not subject to any explicit statutory duties with respect to biosecurity under the honeybee health framework. For instance, there are no obligations related to the disposal or storage of hive products or their containers. With respect to the bees themselves it has previously been established that bees swarming away from their hives and later returning remain the property of the owner so long as she has the power to pursue them. See Reid (n 26) 17-18.

69 For example for cattle (n 8). 
strictly have to be reported by those handling honey, under section 3 of the 2006 Order)..$^{70}$

As can be seen, there are some important differences in the way that honeybee disease risks are managed as compared with those of animals within the traditional animal health paradigm. One implication of this is an increased risk of disease prevalence and spread and reduced ability to prevent and control disease and pest outbreaks. The differing characteristics of honeybees compared with other animals within the framework appear to have placed them outside of the framework despite the importance of pest and disease control to honeybee health. Unlike other animals within the framework honeybees are not, in most cases, commercially managed and honey production is not an economically significant industry. This predominantly non-commercial status of beekeepers has been seen as reason to avoid additional mandatory controls and in particular compulsory registration. Beekeepers were thought not to support mandatory registration, seeing it as ineffective, unnecessary or an inappropriate intrusion into a private hobby ${ }^{71}$ and registration has been considered to pose an inappropriate regulatory burden on small-scale keepers ${ }^{72}$ (though as noted, registration of small scale beekeepers in certain other jurisdictions has been required).

An additional complication concerning honeybees and the animal health framework concerns the nature of 'kept' animals. ${ }^{73}$ Animal health regulations apply to animals which are considered 'kept'; this implies that they are subject to human control and that the keeper has a large degree of control over the conditions and movement of their animals. ${ }^{74}$ Though not commercially managed, most honeybees in England and Wales are managed by beekeepers and have consequently not been considered as 'wild'. These bees are maintained in hives and in this sense may also be viewed as 'kept'. In comparison with other kept animals however, they are not subject to the same degree of control since honeybees leave the hive to forage and their movements are in this sense not within the control of the keeper and perhaps not necessarily within their knowledge. ${ }^{75}$ This makes the application of controls to honeybees and beekeepers somewhat different from those that may be applied to traditional livestock animals. A further difficulty is that although the majority of honeybees are managed, a [presumed to be] small number of honeybees are wild and/or feral and may have contact with managed honeybees (discussed below), in contrast with the position for many livestock animals. The presence of 'feral' honeybees in the country

70 FERA, Information Note AFB infection (n 64).

71 See for example, Hansard 29 April 2009, Column 255WH < https://www.publications.parliament.uk/pa/ cm200809/cmhansrd/cm090429/hallindx/90429-x.htm> accessed 3 March 2017.

72 DEFRA, 'Healthy Bees' (n 58).

73 Public guidance from Defra confirms 'You're a sheep, goat, pig or deer keeper if you have responsibility for the day-to-day care and control of these animals. This includes a single animal kept temporarily or as a pet', <https://www.gov.uk/government/collections/guidance-for-keepers-of-sheep-goats-and-pigs > accessed 18 January 2017.

74 Kept animals can also include companion animals and wild animals kept in captivity.

75 In the UK, Couvillon and others report in their study 'the mean distance foragers travelled for pollen was $1,074 \mathrm{~m}$, whereas the overall mean distance foragers travelled for nectar was 1,408 m'. See Margaret Couvillon and others, 'Honeybee Foraging Distance Depends On Month And Forage Type' (2015) 46 Apidologie 6. 
has been given as a further argument that a mandatory registration system would be invalid.

\subsection{Bees as pets within the framework for animal welfare}

Keeping bees in hives and maintaining their housing and food supply implies an assumption of care and it might then be seen that the primary responsibility for health and welfare lies with the keeper. If the majority of honeybees are managed on a hobbyist basis, might they be better understood as pets? In this case, an alternative possibility for regulating honeybee health is within the framework for animal welfare.

Of particular relevance to the identified problems concerning honeybee health, the duty established under the AWA includes protection of animals(s) from 'pain, suffering, injury and disease. ${ }^{76}$ This duty to prevent diseases is perhaps wider in scope than the detailed provisions established within the animal health framework, but is also less precise. In this case the argument that a regulatory burden should not be imposed because of the non-commercial nature of beekeeping is not tenable since regulations are applicable to other animals kept on a similar basis, such as cats and dogs. The duty of care has been clarified in various codes of practice for common pets (such as cats and dogs) as well as for some livestock animals. ${ }^{77}$ Applying this responsibility to beekeepers could potentially establish a legal requirement to provide appropriate housing (with respect to hives), to maintain awareness of, and follow, good husbandry practices to prevent diseases and to act appropriately to treat diseased colonies. Although the AWA is concerned with the welfare of animals at an individual level, for honeybees the duty with respect to protection from disease could support colony health.

As noted previously, as well as imposing a duty of care, the Act creates an offence of causing unnecessary suffering. ${ }^{78}$ Potentially in this case, maintaining low husbandry standards and not preventing or treating the impact of pests and diseases could lead to an offence; the fact of disease presence causing animals to suffer is generally recognised. ${ }^{79}$ The offence applies only to 'protected animals'-defined in section 2 as those which are

a, Commonly domesticated in the British Islands

b, Under the control of man whether on a permanent or temporary basis or,

76 AWA, s 9(2)(e). See generally AWA section 9: Duty of person responsible for animal to ensure welfare.

77 See for example DEFRA, Code of Practice for the Welfare of Dogs (2009) < https://www.gov.uk/govern ment/publications/code-of-practice-for-the-welfare-of-dogs $>$ and DEFRA, Code of Practice for the Welfare of Cats (2009) <https://www.gov.uk/government/publications/code-of-practice-for-the-welfare-ofcats $>$ (both accessed 2 March 2017) . Farm animal welfare is further provided for by the Welfare of Farmed Animals (England) Regulations 2007 (SI 2007/2078) made under s 12 of the AWA. AWA, Under s 4(1) a person commits an offence if

(a) an act of his, or a failure of his to act, causes an animal to suffer,

(b) he knew, or ought reasonably to have known, that the act, or failure to act, would have that effect or be likely to do so,

(c) the animal is a protected animal, and

(d) the suffering is unnecessary.

79 This fact is apparent in the AWA. See also McEldowney, Grant and Medley (n 1) ch 11. Clearly though the presence of the requisite mens rea would be a crucial question in establishing the offence. 
c, Not living in a wild state.

Potentially, honeybees could fall within the scope of 'protected animals' bringing them within the scope of the offence (but see below on the limitations of section 1). Although it may be arguable whether managed honeybees are 'living in a wild state', given their foraging nature, ${ }^{80}$ it is more straightforward to suggest that managed honeybees are under the control of man, at least on a temporary basis. In a similar way the section 9 duty is applicable where a person exercises responsibility for the animals on a permanent or temporary basis. ${ }^{81}$ Applying the existing criteria would appear to offer protection to managed bees although, as in animal health, this is complicated by the fact that honeybees are subject to less control than other kept animals but at the same time not 'wild' in the usual sense (see further below). ${ }^{82}$ On the other hand, section 2 might also be applied to feral honeybees even though these are understood to be living in a wild state. For the purposes of the AWA, the explanatory notes make clear that, with particular reference to cats and dogs, the term 'commonly domesticated' is intended to include feral animals. Animals of a commonly domesticated kind are in this context to be considered as protected animals whether they are under the control of man or not. The notes further provide:

Kinds of animals which are to be considered commonly domesticated in the British Islands are those whose collective behaviour, life cycle, or physiology has been altered as a result of their breeding and living conditions being under human control, in the British Islands, for multiple generations. ${ }^{83}$

80 The question of whether they are domesticated may also raise difficulties, with both issues giving rise to questions about whether the population of honeybees could sustain itself without being managed and whether honeybees are reliant on beekeepers to meet their needs as, for instance, cats and dogs are. On this point, Robertson notes that New Zealand has produced legislation that expressly recognises a distinction between domesticated and feral cats, see $\mathrm{Ch}$ 5. It is frequently recognised though that managed colonies are not self-sustaining. Robertson (n 11). See also Nieto and others (n 47). and see (n 82) and Thompson, Budge and Biesmeijer (n 47).

81 The term 'protected animals' does not apply with respect to the duty under s 9. This refers to the duty owed by the person responsible for those animals which, under s 3 , means that they are responsible 'on a permanent or temporary basis. A person who owns or is in charge of an animal will be considered to be responsible for it if they have assumed responsibility for the animal's day-to-day care or for its care for a specific purpose'

82 Even in this instance (concerning temporary control) the greater degree of freedom displayed by honeybees makes the matter less straightforward than for most companion animals. And see Steele v Rogers (1912) 76 JP 150 in which the court held that temporary control was not being exercised in the case of a beached whale attacked with a knife while still alive since control implied more than inability of the animal to escape.

83 Note 14, Explanatory Notes to the Animal Welfare Act 2006. Feral bees might also be protected animals for the purpose of this Act if they are interpreted as falling in the definition of 'Not living in a wild state'. The Explanatory Notes provide that this term 'is intended to cover those animals which may have ceased to be under the control of man, and therefore do not fall within section 2(b), but are not yet living wild, including (though not limited to) animals which have escaped, for example from a zoo or circus.' It may be arguable that feral honeybees are 'escaped' in this sense though it is not clear whether they can be considered as living wild. See also Couvillon and others (n 75). 
The likely application of this is very limited given that it is only the offence and not the general duty that it would apply to and that this requires the necessary mens rea. In practice it is unlikely to offer protection to unmanaged, feral honeybees, but the conceptualisation of domesticated animals within the Act does highlight further the difficulty of categorising honeybees which arises from their ambiguous positions.

More significant and difficult to establish, would be that the act or omission caused 'unnecessary suffering', a requirement that is central to the more general applicability of the Act to honeybees. The most immediate limitation with the current implementation of the Act at all-applicable to both the duty under section 9 and the offence under section 4 -is that while section 1 enables the definition of 'animals' to be extended to include invertebrates (and therefore honeybees) no measure of this nature has been introduced. Extending the definition would require that the regulatory authority be satisfied on the basis of scientific evidence that the animal in question is of a kind that is capable of experiencing pain or suffering. ${ }^{84}$ In two jointly heard cases concerning the Hunting Act 2004 the Court of Appeal, while finding that hunting hares, foxes, deer and mink would impact on their welfare, cited the finding of the Burns Inquiry that there was a lack of firm scientific evidence to demonstrate this. $^{85}$ This position is reinforced in the explanatory notes to the AWA which provide

The Act will apply only to vertebrate animals, as these are currently the only demonstrably sentient animals. However, section 1(3) makes provision for the appropriate national authority to extend the Act to cover invertebrates in the future if they are satisfied on the basis of scientific evidence that these too are capable of experiencing pain or suffering. ${ }^{86}$

Relatively recent research has attempted to show that honeybees are capable of experiencing suffering, ${ }^{87}$ but given the reluctance in law to recognise that several common mammals have this capacity the prospect of the law being extended in this way appears limited.

Honeybees again occupy a difficult position with respect to legal categorisation. Although the non-commercial basis and manner in which most of the UK's honeybees are kept might potentially bring them within the scope of the AWA, with positive implications for disease prevention and control, and perhaps a more readily acceptable level of regulatory intervention, they do not easily fit here. As invertebrates they have not been included in implementing regulations and the likelihood

84 s.1(4)

$85 R$ (on the application of Countryside Alliance and others) v HM Attorney General and Secretary of State for Environment, Food and Rural Affairs and $R$ (on the application of Frances Derwin and others) v HM Attorney General and Secretary of State for Environment, Food and Rural Affairs [2006] EWCA Civ 817; Lord Burns, Report of the Committee of Inquiry into Hunting with Dogs in England and Wales (HM Stationery Office 2000) ch 5 .

86 Note 11, Explanatory Note.

87 Melissa Bateson and others, 'Agitated Honeybees Exhibit Pessimistic Cognitive Biases' (2011) 21 Current Biology 1070; Kelsey Horvath and others, 'Invertebrate Welfare: An Overlooked Issue' (2013) 49 Annali Dell'istituto Superiore Di Sanità, 9; See also Jason Castro, 'Do Bees Have Feelings?' Scientific American (August 2 2011). 
of their meeting the 'experiencing suffering' threshold is questionable. Even if requisite data establishing sentience was accepted it is not entirely clear whether honeybees could comfortably be incorporated into the framework without making a distinction between managed and unmanaged bees of questionable usefulness (this in turn raises questions of the distinction between 'feral' and 'wild', discussed below).

\subsection{Conservation and honeybees as wild animals}

The final framework to consider, given the limitations observed in the application of the animal health and welfare frameworks is that of wildlife and conservation. As a species suffering diminishing numbers, with populations living wild and given their role in maintaining healthy ecosystems, it might in some circumstances be appropriate to consider honeybees from a conservation perspective.

Although the majority of honeybees in England and Wales are managed by beekeepers, this is not the case for all honeybees: some may be seen as wild or at least as 'living wild' and managed bees have themselves been seen as 'semi-wild' or as possessing characteristics that may distinguish them from other kept animals, potentially bringing them within the conservation paradigm. At a broader conservation level the foraging nature of bees means that habitat conservation may be important not only as a matter for wild bee conservation but also for managed bees.

It can be observed from the outset that there is no provision within the framework of conservation specifically for the protection of honeybees (including from pests and diseases or specific habitat measures). In the WCA 1981, 'wild animal' means any animal which is or was living wild and is therefore unlikely to apply to managed honeybee colonies, but might apply more widely to unmanaged bees including, possibly, feral bees. ${ }^{88}$ The offences in the WCA extend only to the intentional killing, taking or injuring of listed species rather than to broader protections and honeybees are not included in this list. Within the framework of the CRoWA 2000 the priority terrestrial invertebrate species currently listed for the purpose of the UK Biodiversity Action Plan (now the post-2010 Biodiversity Framework) includes a number of bee species but not honeybees. ${ }^{89}$ The 'European protected species' listed under the Habitats Regulations does include invertebrates ${ }^{90}$ but Annex 2 does not include the honeybees (nor any other bee species).

Within this framework honeybees are not afforded ad hoc protection in the same way as some selected species, such as badgers. They are also excluded from conservation laws which focus on species prioritised because of their low population levels and the sustainability of the species. The presence of feral bees is, further, a particular problem with respect to conservation. A major assessment of the status of bees in Europe-the 'European Red List of Bees'-classified the European honeybee as

88 The applicable Schedule 5 includes invertebrates though again not honeybees.

89 Joint Nature Conservation Committee and DEFRA (on behalf of the Four Countries' Biodiversity Group), UK Post-2010 Biodiversity Framework, (July 2012), < http://jncc.defra.gov.uk/page-6189> accessed 18 January 2017. For lists of priority species and habitats see <http://jncc.defra.gov.uk/page$5705>$ accessed 18 January 2017. 
'data deficient'. ${ }^{91}$ The justification for this, despite the bees having native distribution throughout much of Europe, was that

it is not known whether the species in Europe currently still occurs in the wild, due to the introgression of managed and feral colonies with wild colonies and the fact that the wild population may not be self-sustaining. ${ }^{92}$

The assessment further notes that some colonies living in the wild cannot be considered as wild since they may contain species that have escaped from a managed colony. This categorisation implies a distinction between those bees that are living wild' and those which are 'truly wild'. In this case, because their status as 'wild' is disputed, honeybees that are not managed and may appear to be living wild are effectively excluded from assessment, even if population numbers for the species would suggest that conservation efforts are needed. This categorisation of wild/non-wild honeybees is not however universally accepted: Thompson and others note that:

by contrast [with managed colonies], feral bees live in an unmanaged state so, like any other wild creature, are subject to natural selection. Bees that are illadapted to local conditions or disease will die out, while those that are welladapted will survive. $^{93}$

This view of feral honeybees as distinct from 'domesticated' species potentially supports a view of all unmanaged bees as 'wild'. ${ }^{94}$ The notion that the prevalence of managed honeybees means that they should be excluded from conservation efforts because these bees are 'unnatural' can also be challenged: first because managed honeybees play an important ecosystem role and, second, because beekeeping itself plays an important role in safeguarding the species overall. ${ }^{95}$

\section{PARAMETERS OF THE TRIPARTITE PARADIGM AND CONTEMPORARY CHALLENGES}

As highlighted in the preceding section, the regulation of animals becomes problematic where the animals in question do not fit well into existing frameworks. This section further explores the parameters of those frameworks and argues that problems such as those highlighted can be viewed as a result of the disparities between the historical development of these frameworks and contemporary regulatory challenges. In animal health it is the commercial significance of animals linked with the historical, economic and public health focus of disease control measures which determines the parameters of regulation rather than concern for the impact of disease on animals or animal populations per se. The traditional priorities of the animal health framework clearly do not apply to honeybees: although honeybees do make a recognised

91 Nieto and others ( $\mathrm{n} 47$ ).

92 ibid 17.

93 Thompson, Budge and Biesmeijer (n 47).

94 Which would also fit the definition used in the WCA.

95 Rodolfo Jaffé and others, 'Estimating The Density of Honeybee Colonies Across their Natural Range to Fill the Gap in Pollinator Decline Censuses’ (2010) 24 Conservation Biology 583. 
economic contribution through their pollination role this is indirect, in contrast to the direct economic relevance of livestock. The non-commercial status of the majority of beekeepers has been seen as a reason to avoid additional mandatory controls and this perspective is reinforced in the case of several other species. For example, mandatory controls apply to 'micro-pigs' kept as pets, for which a movement licence is needed in the event that the animals are moved from one area to another and there is a legal obligation to keep records of the movement of those animals on or off the registered premises. ${ }^{96}$ These non-commercially kept micro pigs are distinguished from honeybees because of the possibility of spreading diseases to commercially reared pigs.

Somewhat similarly to honeybees, pigeons can also be managed, but maintain contact with wild pigeons for example where they are kept but released for the purpose of racing. Although these pigeons are not economically significant and are kept on a relatively small scale, in the same way as honeybees, their regulatory position is somewhat different again because they can be carriers of paramyxovirus (PPMV), a notifiable disease which can be introduced to racing pigeons through contact with wild pigeons. PPMV can in turn be a disease risk for chickens and for this reason pigeons, including racing pigeons, are brought directly within the animal health framework through express inclusion within the Poultry (England) Order 2003. This imposes on keepers some specific record keeping and vaccination requirements as well as the more general requirements of the Order. It is the implications for chickens, and not pigeons (whether kept as 'pets' or wild) which is the focus of these measures and the basis for inclusion within animal health. In these examples it is the direct implications for livestock animals that bring the animals into the animal health framework. Voluntary arrangements are in place for some other animals (for instance alpacas and chickens) in circumstances where this risk to commercial production is less of a concern. ${ }^{97}$

Animal diseases are, though, of much broader concern and the means of control more complex than this focus suggests. Wild animals have been identified as a major source of emerging diseases ${ }^{98}$ and can act as vectors and reservoirs for diseases affecting livestock and human health. ${ }^{99}$ In this sense animal diseases in wild animals must be a concern within the conventional priorities for animal health. As has been controversially demonstrated through efforts to control the impact of bovine tuberculosis through the control of badgers, the presence of disease in wildlife can have significant implications for livestock health. Given the emerging nature of this issue and the reactive nature of the animal health framework efforts to broaden

96 Requirements are summarised in DEFRA guidance, 'Keeping a Pet or Micropig' < https://www.gov.uk/ guidance/keeping-a-pet-pig-or-micropig > accessed 18 January 2017.

97 See Animal Health and Veterinary Laboratories Agency, Backyard Poultry in Great Britain: General Guidance < https://www.gov.uk/guidance/avian-influenza-bird-flu> accessed 03 March 2017.

98 William Karesh and others, 'Wildlife Trade and Global Disease Emergence' (2005) 11 Emerging Infectious Diseases 1000.

99 One of the most prominent and controversial examples of this in the UK is the case for badgers, who act as a reservoir for bovine tuberculosis. See further Richard Horan and Christopher Wolf, 'Joint Management Of Wildlife And Livestock Disease' (2008) 41 Environmental Research Economics 47; Peter Daszak, Andrew Cunningham and Alex Hyatt, 'Anthropogenic Environmental Change And The Emergence Of Infectious Diseases In Wildlife' (2001) 78 Acta Tropica 103. 
surveillance or other measures to wild animals have been limited and slow to develop. Disease surveillance in wild animals is undertaken by a patchwork of organisations and where it does occur surveillance and monitoring is often based upon voluntary projects and initiatives. ${ }^{100}$ The framework of animal health has not generally extended to wildlife and it has no relationship with habitat conservation or the protection of ecosystem services (which include disease regulation) ${ }^{101}$ which may help to manage these risks.

While the animal welfare framework may in some respects be better suited than animal health to the regulation of managed honeybees, its parameters leave uneven coverage for honeybees overall which is perhaps untenable given that managed and unmanaged populations live side by side. More broadly, provision for wild animal welfare is scant. Whereas wild animals may, at least in some cases, more easily satisfy the sentience requirement (than honeybees), they will otherwise be excluded because of the continuing legal distinction between the duties and responsibilities that are owed to 'animals' as distinguished from 'wild animals'. The question of health and disease specifically is also linked with animal welfare since the impact of disease is recognised as having a detrimental impact on welfare. ${ }^{102}$ The AWA 2006 excludes animals where they are 'living wild'. The Department of Environment, Food and Rural Affairs (DEFRA) has confirmed that possible future laws or other measures addressing disease control should only be applicable where there is a threat to native species-and primarily priority species-at a population level. ${ }^{103}$ It will not be applied to prevent suffering of individual animals though this is one of the tenets of the duty within the AWA (for the animals to which it applies). While the UK is often recognised as having a progressive attitude to animal welfare ${ }^{104}$ there are limitations on how far this extends to wild animals and this is clearly the case where the impact of diseases is concerned.

In the case of conservation a starting point of utility, seen in the historical development of the framework, is problematic for honeybees since they have not been (of course) subject to hunting, collecting or other types of use that formed the early basis of protection for some species. The utility of bees as pollinators, more recently recognised, has not brought them within such measures. This perspective similarly provides limitations on the protection offered to other wild animals. Schaffner, for instance, highlights this situation for rabbits, in the US context: while companion

100 Parliamentary Office of Science and Technology 'Wildlife Diseases', Postnote, April 2008, Number 307. The GB Wildlife Surveillance Partnership includes Animal Health and Veterinary Laboratories Agency (AHVLA), Scottish Agricultural College (SAC), Institute of Zoology (IoZ), the Food and Environment Research Agency (FERA), the Centre for Environment, Fisheries and Aquaculture Science (Cefas), the Wildfowl and Wetlands Trust (WWT), Natural England (NE) and Forestry Commission (FC) (See further <https://www.gov.uk/government/publications/wildlife-disease-surveillance-reports-2014> accessed 03 March 2017 and see Chris Cheffings and Richard Ferris, Wildlife Diseases and Biodiversity (JNCC 13 D03, Joint Nature Conservation Committee 2013).

101 Alcamo and others (n 41) ch 2.

102 The relevance of disease as a welfare is recognised in the AWA. On the evolution of animal welfare from prevention of cruelty to a welfare approach see for example Robertson (n 11) ch 5.

103 DEFRA, England Wildlife Health Strategy a strategy for tackling the impacts of wildlife diseases in England (June 2009).

104 For perspectives from the USA and France see Jean-Marc Neumann, 'The Legal Status of Animals in the French Civil Code' [2005/1] Global J of Animal L and Schaffner (n 15). 
rabbits are afforded protections under anti-cruelty laws, rabbits which are 'free roaming' and living wild have very few protections and are addressed by the law primarily from a resource perspective and with no assumption of sentience. ${ }^{105}$

The assumption that wild animals be left outside of legal controls unless their relationship with humans is such that responsibilities would arise also has implications for wild animal conservation and means that a clear understanding of, and distinction between, those animals that are wild and those that are not, is crucial. A complication here has been the distinction between animals which are 'living wild' and those that are 'truly wild' and the assumption that only 'truly wild' populations are to be subject to conservation efforts. The presence of managed honeybees provides an 'alternative' population which has effectively excluded them from the perceived need for wider conservation efforts. On this basis it is not surprising that there are no provisions applicable to honeybees but there is also no protection of 'wild' honeybees despite the fact that the population of wild honeybees is recognised as threatened and perhaps close to extinction. ${ }^{106}$

The limitations of conservation are reiterated with respect to the question of wildlife diseases. These pose an important threat to biodiversity but existing legal frameworks typically offer no clear response to this issue. ${ }^{107}$ Domestically in England and Wales (and more widely in the UK) there is no strategic framework for diseases affecting wildlife. Wild animals and diseases of wildlife may be the subject of specific measures where a risk is posed to livestock or public health ${ }^{108}$ but there is no overall legal basis for preventing diseases of wildlife for the sake of species protection or biodiversity. Despite the implications for biodiversity and despite the recognised relationship between disease prevalence and habitat integrity, wildlife diseases are not addressed at all within conservation laws. ${ }^{109}$ These laws might become relevant in a reactive context, if the impact of disease has been sufficient to threaten the population numbers of a species which is or becomes prioritised but they offer neither direct nor preventative protection. The recent Law Commission consultation on wildlife law noted, with respect to disease control legislation, that the principal focus here is the protection of agriculture and public health and a review of the relevance of such measures to wildlife was expressly excluded from the project. ${ }^{110}$

The presence of feral animal populations further poses difficulties in the context of the existing frameworks. As noted, for honeybees the presence of feral populations was seen as a barrier to regulation within animal health and conservation. Similarly, the position is complicated for wild boar. While commercially kept wild boar fall within the animal health framework, feral wild boar are not subject to equivalent

See Patricia Farnese, 'The Prevention Imperative: International Health and Environmental Governance Responses to Emerging Zoonotic Diseases' (2014) 3 TEL 285.

Animal Health Orders, for example, may authorise culling of wildlife where they pose a disease risk to 'other animals' as has been the case, for instance with badgers under the The Tuberculosis Eradication (Wales) Order 2009 (SI 2009/2614). See s 21 of the Animal Health Act 1981.

9 Chomel and others for instance note that conservation of habitats is critical for preventing emergence of new reservoirs or amplifier species. Bruno Chomel, Albino Belotto and Francois-Xaxier Meslin, 'Wildlife, Exotic Pets, and Emerging Zoonoses' (2007) 13 Emerging Infectious Diseases 6. 
disease controls - despite the fact that they can be affected by and transmit endemic and exotic diseases - because the risk they pose to domestic pigs is considered to be low. ${ }^{111}$ While the feral wild boar themselves are not subject to control, their presence does not impact the requirement that pigs (including boar) be registered (though the likelihood of kept and feral boar interacting is much less than for honeybees because of the closer degree of control that kept pigs are subject to). In the framework of animal health, feral populations complicate the regulatory picture because while their presence might have implications for the health of kept animals they cannot be managed in the same way as other farmed animals. At the same time, these populations may be impacted themselves by animal diseases but are unlikely to be subject to disease control on this basis.

Feral animals also present difficulties in the context of animal welfare. Whereas this framework provided opportunities for protection in the case of feral honeybees the position is not the same for all feral animals. Control of feral wild boar is a matter for local landowners: ${ }^{112}$ concerns have been raised about the welfare implications of shooting feral wild boar but DEFRA guidance confirms that 'there is no legislative vehicle under which specific welfare protection for feral wild boar can be introduced'. By contrast farmed wild boar along with other pigs will attract animal welfare measures. This raises a tension in the parameters of animal welfare-feral wild boar although related to domesticated species effectively 'lose' the protection of animal welfare because in this context they are 'living wild' and the limitations of wild animal welfare therefore apply. ${ }^{113}$

The relationship between feral and wild species is problematic in the framework of conservation because although they are 'living wild', feral animals are considered to be distinct from 'truly wild' animals based on the notion that their populations may not be self-sustaining, descending as they do from domesticated animals. In addition the presence of feral animals has been seen to undermine the conservation of wild animal populations where interbreeding affects the genetic composition of wild species. The distinction between feral or other unmanaged populations and those that are truly wild may not always be easy to establish however and even if it is, the exclusion of certain populations may not always be straight forward in its conservation implications. The presence of hybrid animals and their delineation from the 'truly wild' animals is another in which the distinctions in conservation can be problematic. Trouwborst has discussed the complexities surrounding the status of wolfdog hybrids within EU and international conservation law. ${ }^{114}$ Hybrid animals may pose a threat to wild species but, as examined in the case of wolf-hybrids, are not explicitly addressed in the relevant conservation laws. In this example, changes to enable more effective control of feral animals may be necessary to address the problems associated with hybrid species but as has been seen in the case of

111 DEFRA, Feral Wild Boar in England: An Action Plan (2008).

112 ibid.

113 But this too points to an internal inconsistency since the description of 'feral' in the AWA implies that, in the narrower context of the s 4 offence, protections may apply.

114 Arie Trouwborst, 'Exploring the Legal Status of Wolf-Dog Hybrids and Other Dubious Animals: International and EU Law and the Wildlife Conservation Problem of Hybridisation with Domestic and Alien Species' (2014) 23 RECIEL, 111. 
honeybees the issue is slightly different to that of wolf-dog hybrids, involving domesticated populations of the same species. Trouwborst also notes that in certain circumstances failing to protect wolf-dog hybrids may undermine the conservation status of wolves. These issues point to further questions about the definition of wild animals and what it means to be 'wild'. As noted by Fitzgerald there can be differing legal, cultural and scientific perspectives on the terms 'wild animals' and 'wild' and some animals may be more readily viewed as wild than others. At the same time the law must [or ought to] address issues across the whole range of human interests and not those in only one limited perspective. ${ }^{115}$

\section{CONCLUDING REMARKS}

As has been seen, the parameters of the three main paradigms concerning animals and the law (specifically in the context of the legal system of England and Wales) can be problematic and inconsistent when addressing specific regulatory concerns and species and fail to take into account or respond to modern problems. These paradigms are based on assumptions and categorisations which are no longer compelling: inconsistencies about the presence of sentience, a too narrow focus on the nature of health and disease issues, outdated perspectives on the relationship between humans and wild animals and the true utility of wild animals, and perspectives on the environment and conservation which do not reflect a contemporary acceptance of the interconnectedness of species and the wider role and function of ecosystems and their services.

Limited changes to existing frameworks would help to address difficulties in specific cases. For honeybees, for example, simple changes such as requiring registration of hives or beekeepers would facilitate monitoring and disease management in a way that is more consistent with the approach to disease risks for other animals. Extending the duty of care within the animal welfare framework would likely have an impact on the presence of pests and diseases, although the extent of this is questionable, given the presence of feral and/or wild honeybees.

Both the animal welfare framework and that for conservation could be extended to accommodate some of the challenges discussed. Given the advances in social attitudes towards animal welfare such as those recognised in the passing and upholding of the Hunting Act 2004 (albeit, as noted, with some restraints), the wider exclusion of animals living wild and the provision of only ad hoc protections of wildlife in both welfare and conservation contexts might be viewed as untenable, particularly given that this can lead to inconsistencies even within the same species. Similarly, biodiversity plans and legislative provisions could incorporate strategic planning, horizon scanning, and responsibilities for surveillance and enforcement to tackle wildlife diseases. ${ }^{116}$ Introducing a legal basis for action where disease poses a threat to species or biodiversity would be an alternative means of addressing this particular gap and recognising its wider importance.

115 Fitzgerald (n 13).

116 There is a vast difference here in the importance that has been attached to diseases of wildlife in animals as compared with those occurring in the framework of plant health, such as ash dieback disease and the control of oak processionary moth. 
Given the parameters discussed, the possibility of extending these frameworks turns on legal distinctions such as whether given animals are to be considered 'wild'. Here is where changes must go further than extending existing provision to address the conceptualisation of animals. The assumption that the law should not intervene with wild animals breaks down when it is recognised that anthropogenic activities are exposing wild animals to new risks. The notion that wild animals are 'untouched' and can be distinguished from those 'under the control of man' is stretched in the modern context: this argument has been made lucidly by Harrop who argues that increasing urbanisation, changes in land use and the effects of climate change, including impacts on ecosystems and habitats, mean that the notion of 'wild' is becoming and will become more difficult to assert. ${ }^{117}$ In addition, Robertson argues that the notion that wild animals are not 'utilised' in the way that other animals are, overlooks the fact that 'modern attitudes usually recognise the value of biodiversity to human existence and its importance in ecosystem health and other functions which are inherently valuable to human existence'. ${ }^{118}$ The basis for the continued exclusion of wild animals from measures for animal health and welfare can consequently be questioned along with the conventional distinction between wild and kept animals.

Domestic law however, has been reluctant to move in this direction. The recent review of wildlife law undertaken by the Law Commission, for instance, proposed changes to the WCA which would make it possible to list species in the applicable Schedules for reasons other than extinction risk, including, for instance, as an essential component of an ecosystem. ${ }^{119}$ These changes would go some way to providing greater protection for animals to be protected on the basis of their ecosystem role. Nevertheless, the decision to maintain a distinction between wildlife and habitat protection, with the latter excluded from the review, maintains an unhelpful and impractical distinction between the protection of wild animals and their habitats. Similarly, the difficulties concerning the definition of 'wild' and the presence of feral animals were not addressed.

Possibly more straightforward, but narrower in scope, is the option of extending the existing animal health framework to introduce obligations concerning wild animal disease. This would extend the framework beyond its traditional boundaries and would facilitate an approach that on the one hand would recognise the impact of diseases on the health and consequently welfare of wild animals, and on population levels and biodiversity more broadly. On the other hand, it would allow for a more comprehensive approach to managing diseases relevant to livestock and managed animals: incorporating regulatory obligations and responsibilities within one framework here would provide an opportunity to act more holistically with respect to the pathways and vectors for disease including those affecting farmed animals (and indeed human health). One of the great challenges here would be in addressing questions of responsibility, liability and the cost of regulatory action and potential cost

117 Stuart Harrop, 'Climate change, Conservation and the Place for Wild Animal Welfare in International Law' (2011) 23 JEL, 441. With reference to disease, the extent to which wild animals are exposed to diseases, including exotic and emerging diseases, is driven by anthropogenic activity including changes to land use and increased international trade and travel. 
sharing arrangements, recognising the public good aspect of effective management of animal diseases. This broader framework might also accommodate more flexibility in dealing with those animals occupying more complex, or more ambiguous regulatory spaces, as in the case of wild boar: bringing all wild boar within the same framework could potentially allow for more consistent thinking with respect to welfare as well as in determining the need for, for instance, disease surveillance, on the basis of disease risk.

A more ambitious project would seek a more comprehensive or holistic approach in which the implications of given challenges and risks be assessed with respect to the impact on animals, population levels and in a wider environmental context, for instance, incorporating ecosystems health. There is, in the modern context, no compelling reason why such an approach should not be pursued. Indeed, it has been called for in international policy fora and would be beneficial both to the narrower anthropocentric concerns of the agricultural economy and human health and, to the protection of animals from a broadly defined welfare and conservation perspective. One corresponding approach which has gained traction at the international policy level is the 'One Health' approach which seeks to unite veterinary medicine and public health as well as wildlife and ecosystems health. ${ }^{120}$ This approach specifically addresses problems surrounding health and disease but also demonstrates a way of responding to a given problem which understands the problem in the context of interconnected spheres. Despite its emergence at the global policy level domestic law has not pursued an approach of this type. While the implications of specific issues such as those concerning honeybees, wild boar, or hybrid wolves may be relatively constrained, those concerning the failure to tackle animal categorisations in their modern context and those of emerging challenges such as wildlife disease are of far reaching significance. Extending existing frameworks, perhaps most practically in the framework of animal health, would go some way to addressing these issues but to offer a framework that is broad and comprehensive enough to continue to meet challenges will require more than this.

\section{ACKNOWLEDGEMENTS}

The author would like to thank the anonymous reviewers for their very helpful comments. Errors and omissions remain my own

120 See generally, John Mackenzie and others, One Health: The Human-Animal-Environment Interfaces in Emerging Infectious Diseases: The Concept and Examples of a One Health Approach (Springer 2013). The World Organisation for Animal Health, The UN Food and Agriculture Organisation and the World Health Organisation have expressed commitments to this approach. See for example, The FAO-OIEWHO Collaboration Sharing responsibilities and coordinating global activities to address health risks at the animal-human-ecosystems interfaces, A Tripartite Concept Note April $2010<\mathrm{http}$ //www.who.int/influ enza/resources/documents/tripartite_concept_note_hanoi/en/ $>$ accessed 3 March 2017. Discussing disease as an ecological concept and the inter-relationship between animals, health and ecosystems, see also Angela Yang and others, 'Bridging the Gap Between Conservation and Health' in Serge Morand and others (eds), Socio-Ecological Dimensions of Infectious Diseases in Southeast Asia (Springer 2015). 